\title{
OPEN Surgical outcomes with high and low pulse energy femtosecond laser systems for cataract surgery
}

\author{
Hung-Yuan Lin ${ }^{1,2}$, Ya-Jung Chuang ${ }^{3 凶}$ \& Pi-Jung Lin ${ }^{4}$
}

Currently, there is no clear consensus in cataract surgery if low compared to high energy femto-lasers may enable better capsulotomy quality and induce lower inflammatory response. Therefore, the aim of this study was to compare the intra-operative outcomes achieved with high and low pulse energy femtosecond laser systems for cataract surgery. The charts of 200 eyes of 200 patients aged $68.3 \pm 10.3$ years who had undergone femtosecond laser-assisted cataract surgery using either group 1 high pulse energy: LenSx (Alcon Laboratories) $(\mathrm{N}=100)$ or group 2 low pulse energy: FEMTO LDV Z8 (Ziemer) $(\mathrm{N}=100)$ laser were reviewed retrospectively. Integrity of anterior capsulotomy, classified as (1) complete (free-floating or with minor microadhesions), (2) incomplete and (3) with capsular tears, intraoperative completeness of the clear corneal incisions $(\mathrm{CCl}$, main incision and side port), incidences of intraoperative miosis and incidence of subconjunctival hemorrhage were evaluated and compared between the two groups. The proportion of complete capsulotomies was significantly higher in the group 2 than the group $1(100 \%$ vs $94 \% ; p=0.03)$. The incidences of intraoperative miosis $(0 \%$ vs $19 \%)$ and subconjunctival hemorrhage ( $1 \%$ vs $63 \%)$ were significantly lower in the group 2 than the group 1 ( $p<0.001)$. Completeness of the main incision was comparable $(97 \%$ vs $95 \% ; p=0.721)$ between the two groups. Although not statistically significant, the completeness of side-port incision was slightly better in the group 2 than the group 1 (91\% vs 86\%). Low energy laser system performed significantly better in terms of completeness of capsulotomy, intraoperative miosis and sub-conjunctival hemorrhage, compared with high energy laser; the $\mathrm{CCl}$ outcomes were comparable.

One of the main challenges in phacoemulsification surgery is achieving a continuous curvilinear capsulorhexis ${ }^{1,2}$. Femtosecond laser-assisted cataract surgery (FLACS) has been advocated due to its ability to create a more precise and circular capsulotomy, greater predictability in achieving the desired size and centration of capsulotomy and in turn effective lens position (ELP) as compared to the manual procedure ${ }^{3,4}$. Despite the highly precise capsulotomy outcomes, the occurrence of capsular tags, capsule rupture, associated with FLACS created capsulotomy is not uncommon $^{4-6}$. In addition, femtosecond laser pre-treatment has been reported to be associated with significant intra-operative pupil miosis (pupil diameter $\leq 6 \mathrm{~mm}$ ) in up to $32 \%$ eyes $^{7-9}$.

Femtosecond lasers employ two different patterns of photodisruption: high-energy pulses $(\mu J)$ coupled with low-frequency $(\mathrm{kHz})$ and low-energy pulses $(\mathrm{nJ})$ coupled with high-frequency $(\mathrm{MHz})$. With a high pulse energy, greater spacing between the spots is employed, whereas the low pulse energy laser allows greater number of overlapping smaller sized spots ${ }^{10}$. Unlike most femtosecond laser systems, the FEMTO LDV Z8 femtosecond laser employs low pulse energy (nJ) and a high repetition rate in the $\mathrm{MHz}$ range. Previous studies have reported greater incidence of capsular irregularities and collateral damage using high pulse energies ${ }^{11}$. It has been hypothesized that low energy femtosecond lasers may enable smoother capsulotomy and induce minimal release of inflammatory mediators. Furthermore, femtosecond lasers employ different patient interfaces for the docking step. The use of curved contact interfaces has been found to increase IOP because of corneal compression during the applanation process and create corneal folds during laser cataract surgery leading to incomplete capsulotomy. In contrast, fluid-filled liquid interfaces have been found to prevent corneal folds, improve globe stability, reduce subconjunctival hemorrhage, and lower IOP rise ${ }^{12,13}$. Therefore, this study was aimed at comparing the intraoperative outcomes achieved with Ziemer Z8 (a low energy laser equipped with liquid patient interface) and LenSx (a high energy laser equipped with curved contact patient interface) for cataract surgery.

${ }^{1}$ Universal Eye Center, Zhong-Li, Taiwan, Republic of China. ${ }^{2}$ Ophthalmology Department, Shanghai Ruidong Hospital, Shanghai, China. ${ }^{3}$ Universal Eye Center, Long-Tan, Taiwan, Republic of China. ${ }^{4}$ Universal Eye Center, Taipei, Taiwan, Republic of China. ${ }^{\circledR}$ email: rannyposh@gmail.com 


\begin{tabular}{|l|l|l|l|}
\hline Surgery step & Parameter & FEMTO LDV Z8 & LenSx \\
\hline \multirow{4}{*}{ Capsulotomy } & Diameter & $5.7 \mathrm{~mm}$ & $5.3 \mathrm{~mm}$ \\
\cline { 2 - 4 } & Laser power & $110 \%$ & $6 \mu \mathrm{J}$ \\
\cline { 2 - 4 } & Resection height & $0.6 \mathrm{~mm}$ & $0.5 \mathrm{~mm}$ \\
\hline \multirow{3}{*}{ Mens fragmentation } & Diameter & $5.8 \mathrm{~mm}$ & $4.0 \mathrm{~mm}$ \\
\cline { 2 - 4 } & Laser power & $100 \%$ & \\
\cline { 2 - 4 } & Number of segments & 4 & 6 \\
\hline \multirow{2}{*}{ Paracenthesis } & Laser power & $115 \%$ & $2.4 \mathrm{~mm}$ \\
\cline { 2 - 4 } & Width & $2.4 \mathrm{~mm}$ & $5 \mu \mathrm{J}$ \\
\cline { 2 - 4 } & Laser power & $115 \%$ & $0.9 \mathrm{~mm}$ \\
\hline
\end{tabular}

Table 1. Settings of the laser systems FEMTO LDV Z8 and LenSx.

\section{Materials and methods}

This single-center retrospective comparative analysis included 200 eyes of 200 cataract patients that had undergone FLACS between 2015 to 2018 at our facility. Surgeries before January 2017 were performed using LenSx (Alcon Laboratories, Inc., Fort Worth, TX) laser and surgeries after this date were performed using FEMTO LDV Z8 (Ziemer Ophthalmic Systems AG, Port, Switzerland) laser platform. Moving backward from this date, consecutive case records of 100 eligible patients were included in the LenSx laser group. For the Ziemer Z8 group, we moved forward from the date Ziemer Z8 surgeries were initiated at our facility and collected consecutive case records of 100 eligible patients that meet the recruitment criteria for the laser platform. One eye per patient was included in the study; if both eyes of a patient met the recruitment criteria, the case record of the first eye that was recruited into the study was analyzed.

All surgeries were performed by an experienced surgeon (HYL) at Universal Eye Center, Zhong-Li, Taiwan. The study was conducted in accordance with the tenets of the Declaration of Helsinki for human research and was approved by the Institutional Review Board of Antai Tian-Sheng Memorial Hospital, Taiwan (18-024-B) with a waiver of consent because the data were collected as a part of normal practice care provision.

Inclusion and exclusion criteria. Patients older than 18 years with cataract were eligible to be included in the study. Exclusion criteria included history of glaucoma, retinal detachment, corneal pathology, significant irregular astigmatism, abnormal iris, macular degeneration or retinopathy, lens/zonular instability, previous ocular surgery or trauma, poorly dilating pupil in the operative eye and patients with diabetes mellitus (DM) with uncontrolled fasting blood sugar level $(>200 \mathrm{mg} / \mathrm{dl}$ ). Patients with complicated or hard cataracts (white or black), which in the experience of investigators could influence study outcomes were also excluded. To account for the initial learning curve, first 50 eyes were excluded for the respective lasers.

Femtosecond laser platforms. The LenSx femtosecond laser platform uses a wavelength of $1030 \mathrm{~nm}$, pulse duration of 600-800 femtoseconds, maximum pulse energy of $15 \mu \mathrm{J}$ and pulse repetition rate of $50 \mathrm{kHz}$. It employs three-dimensional spectral domain optical coherence tomography (OCT) and video microscope to perform image guided FLACS. This laser system uses curved lens applanating patient interface with vacuum docking $^{14,15}$.

The FEMTO LDV Z8 femtosecond laser system utilizes the concept of overlapping low-energy near-infrared $(1030 \mathrm{~nm})$ femtosecond laser pulses delivering energy in the nano-joule range $(<1 \mu \mathrm{J})$. With a pulse duration of 250 femtoseconds, the laser runs in the $\mathrm{MHz}$ range applying up to 1 billion pulses per surgery. The laser system's integrated three-dimensional high-resolution spectral-domain OCT imaging system enables visualization/ identification of the precise location of ocular structures intraoperatively. It uses a non-applanating, fluid filled patient interface with vacuum docking ${ }^{16,17}$.

To achieve optimal outcomes, default settings recommended by respective manufacturers were used for both the laser systems. Table 1 enlists the default settings used for both the femtosecond lasers.

Surgical procedure. All procedures were performed under topical anesthesia. Pupil dilation during the surgery was performed using a combination of phenylephrine and tropicamide eye drops (Mydrin-P Eye Drop, Santen.) instilled into the eye 30, 25, 20,15, and 10 min prior to surgery. Ketorolac $0.5 \%$ ophthalmic solution (Acular LS; Allergan, Inc., Irvine, CA) was instilled 4 times/day 3 days before surgery. Femtosecond laser-assisted pre-treatment included lens fragmentation and capsulotomy, clear corneal incision (CCI), and side incisions in both the groups using the femtosecond laser settings enlisted in Table 1, followed by phacoemulsification of the lens nucleus and aspiration of lens cortex. Finally, a foldable intraocular lens (IOL) was implanted into the capsular bag. All surgical procedures were video recorded as a routine procedure. All eyes received the same standardized post-operative regimen for both the laser groups. In addition, laser-assisted astigmatic keratotomy was performed in patients with significant amounts (between $-0.75 \mathrm{D}$ and $-2 \mathrm{D}$ ) of pre-existing corneal astigmatism [43\% (43/100 eyes) in the LenSx laser group and 56\% (56/100 eyes) in the Z8 laser group, however, there was no statistically significant difference between the two groups, $\left.\mathrm{X}^{2}(1, \mathrm{~N}=200)=2.89, \mathrm{p}=0.09\right]$. 
Free floating capsulotomies or those with micro-adhesion

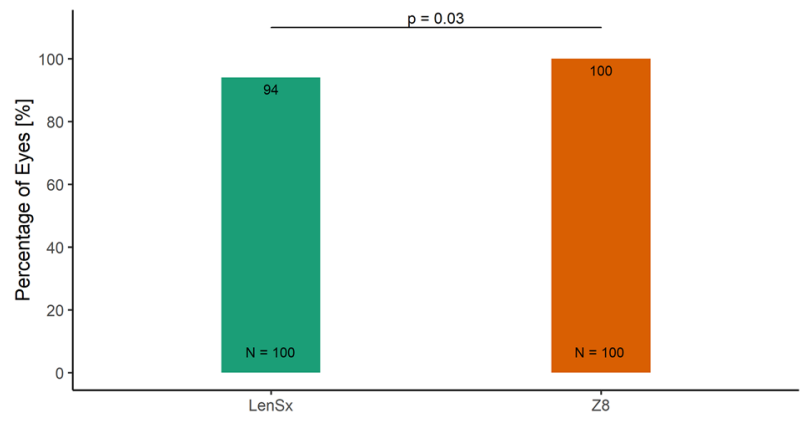

Figure 1. The proportion of eyes with free-floating capsulotomies or those with micro adhesions in the LenSx and the Z8 laser group.

For LenSx laser group, the femtosecond laser portion was performed in a different room adjacent to the operating room. In contrast, the $\mathrm{Z} 8$ laser platform allowed the whole surgical procedure (both laser and manual parts of the surgery) to be performed in the same operating room and under sterile conditions.

Study outcome measures. The videos of all surgeries were retrospectively reviewed, and the following data was collected. Integrity of anterior capsulotomy was recorded as: (1) complete treatment pattern (complete $360^{\circ}$ cut as free-floating capsulotomy or with minor microadhesions, not influencing the free-float), (2) incomplete treatment pattern (femtosecond laser cut not visible in a certain section of the anterior capsulotomy) and (3) with capsular tears. CCI parameters included completeness of main incision and side ports, evaluated based on resistance experienced by the surgeon when entering the incision. If the incision was easily opened by blunt tip of the viscoelastic cannula (Viscoat, (Alcon Surgical, Inc., Fort Worth, TX), it was defined as 'complete' and if the resistance was such that the surgeon had to use a knife to open the incision, it was considered as 'incomplete'. Additionally, the surgeon also recorded the presence of sub-conjunctival hemorrhage and intraoperative miosis (defined as the inability to visualize the capsulotomy margin before opening the main incision). Cases where the capsulotomy was not visible anymore after the laser pre-treatment, were considered as cases manifesting miosis.

Statistical analysis. Data analysis was performed using SPSS software for Windows version 17.0 (SPSS Inc., Chicago, IL). Categorical data were analyzed using Chi-Square test; however, Fisher's exact test was used in cases where more than $20 \%$ of the cells had expected cell values of less than 5 or if the expected value in any cell of the contingency table was less than 1 . In case of continuous variables, normality of the data was checked using Kolmogorov-Smirnov test and quantile-quantile plots. For normally distributed scale data, independentsample $t$ test was used to compare the means between the two groups. All P-values were two-sided and were considered statistically significant when less than 0.05 . The sample size was calculated using literature reported incidence of free-floating capsulotomies achieved with LenSx laser (average 88.4\%) ${ }^{2,18-20}$ and Ziemer Z8 laser (average 98.7\% $)^{21,22}$. Using these reported values for the two lasers, sample size calculations were performed with two-sided alpha of 0.05 and $80 \%$ power which revealed a total sample size of 190 ( 95 in each group). Accordingly, we chose a sample size of 100 in each group.

\section{Results}

A total of 200 eyes of 200 patients (94 males and 106 females) with a mean age of $68.3 \pm 10.3$ years were included in the study. The mean age of the participants in the LenSx and Z8 group were $64.4 \pm 9.9$ and $61.7 \pm 11$ years respectively. The difference between the groups in terms of age was not significant $(t(196)=1.79 ; \mathrm{p}=0.07)$.

The number of free-floating capsulotomies was significantly higher (100\%) in Z8 group as compared to $94 \%$ in the LenSx group $(p=0.03$, two-sided Fisher's exact test Fig. 1). Other capsulotomy parameters including incomplete treatment pattern ( $0 \%$ vs $5 \%$ in Z8 and LenSx respectively) and capsular tears ( $0 \%$ vs $1 \%$ in $\mathrm{Z} 8$ and LenSx respectively) were also found to be lower in Z8 laser group; however, the differences were not statistically significant ( $\mathrm{p}>0.05$, two-sided Fisher's exact test).

Compared to $19 \%$ eyes treated with LenSx laser system, none of the eyes experienced intra-operative miosis in the Z8 laser group $\left(X^{2}(1, N=200)=18.843, p<0.001\right.$, Fig. 2$)$. The LenSx laser group had a significantly greater incidence of subconjunctival hemorrhage, compared to $Z 8$ group $\left(63 \%\right.$ vs $1 \%: X^{2}(1, N=200)=85.501$, $\mathrm{p}<0.001$, Fig. 3).

Completeness of the main incision was observed to be comparable between the two groups (97\% in the $\mathrm{Z} 8$ group and $95 \%$ in LenSx group; $p=0.721$ ). The outcomes for the completeness of side-port incision were slightly better in the Z8 group (91\%) than in the LenSx group (86\%), however the difference was not statistically significant $\left(X^{2}(1, N=200)=0.786, p=0.375\right.$, Fig. 4$)$. 


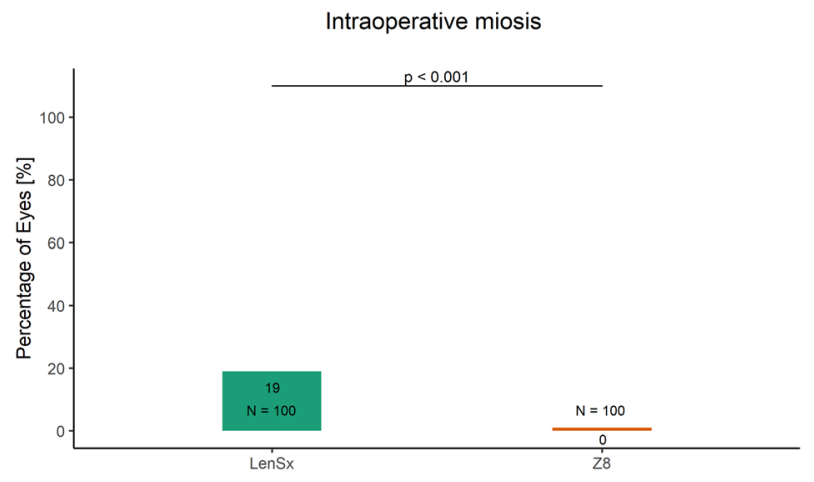

Figure 2. The proportion of eyes with intraoperative miosis in the LenSx and the Z8 laser group.

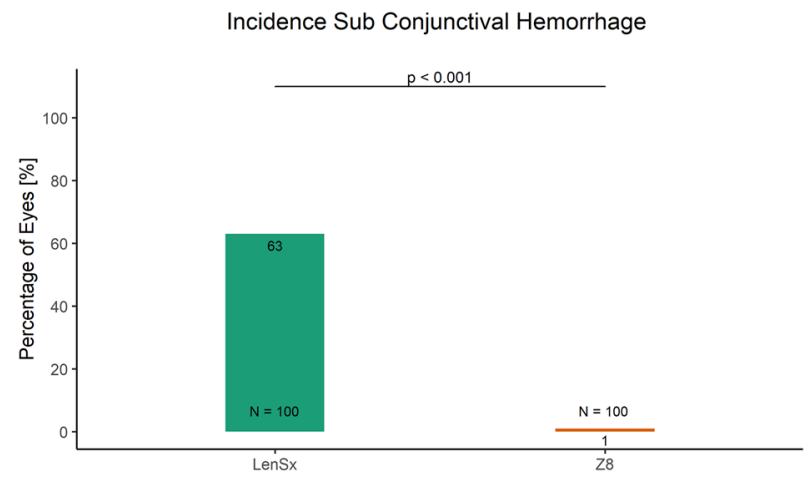

Figure 3. The proportion of eyes with incidence of subconjunctival hemorrhage in the LenSx and the Z8 laser group.

A - CCl (Main Wound complete)

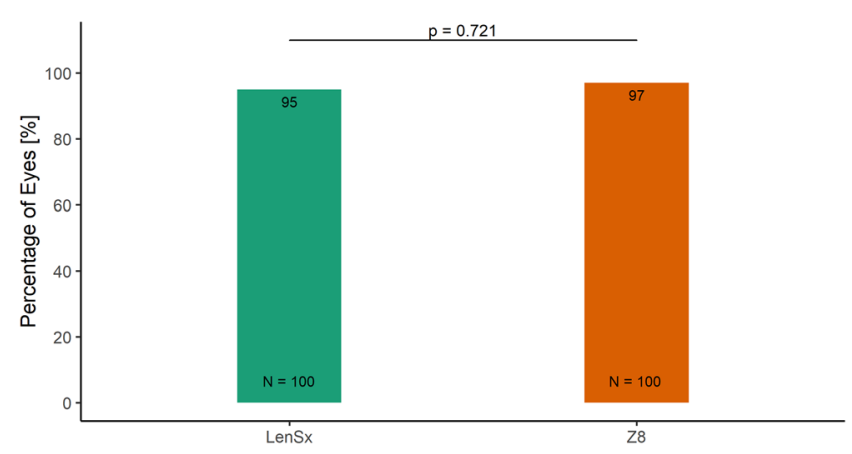

B - CCl (Side Port complete)

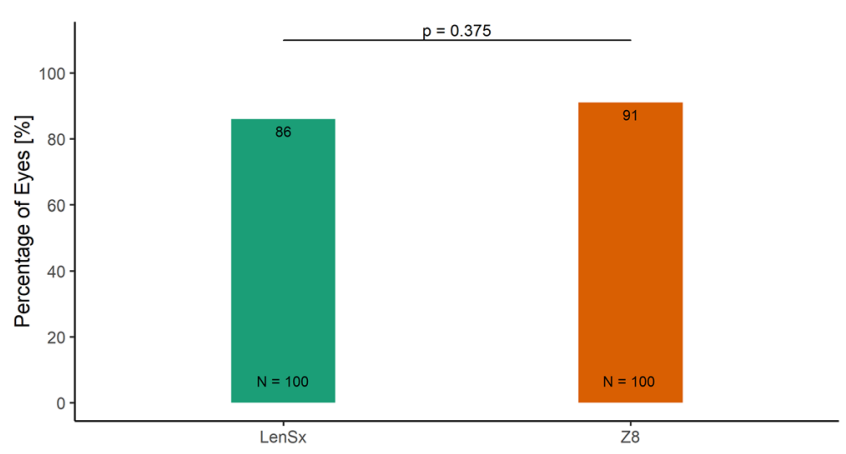

Figure 4. The proportion of eyes with complete CCI in the LenSx and the Z8 laser group (A) Main incision. (B) Side-port.

\section{Discussion}

While numerous studies have provided substantial evidence for the safety and efficacy of FLACS, several complications specific to femtosecond lasers have been documented ${ }^{9}$. Unlike high pulse energy and low frequency femtosecond lasers which emit energy in the microjoule range, the low energy laser combines low pulse energy (in nano Joules) with a high frequency rate to achieve overlapping precisely placed laser spots which has been hypothesized to allow smooth incisions ${ }^{23}$, capsulotomy ${ }^{4}$ and minimal inflammatory response ${ }^{24}$.

The current study was designed to evaluate if there are any differences in high and low pulse energy femtosecond lasers in terms of integrity of capsulotomy, completeness of CCI, incidence of sub-conjunctival hemorrhage and intraoperative miosis.

Capsulotomies. Femtosecond laser enables consistently shaped and well-centered capsulotomies which helps maintain accurate IOL positioning within the capsular bag, thus improving postoperative refractive 
outcomes $^{3}$. However, several capsular irregularities may still occur with laser-assisted capsulotomies including, capsular microadhesions, incomplete and non-continuous treatment pattern, which may compromise the surgical benefits of femtosecond laser technology ${ }^{17}$. Variations in intrinsic laser settings, most importantly pulse energy, have been shown to affect the morphology and capsular irregularities associated with femtosecond laserassisted capsulotomy cutting edges ${ }^{11}$. A comparison of capsulotomy outcomes with high $(15 \mu \mathrm{J})$ and lower pulse energy $(7 \mu \mathrm{J})$ revealed more capsular irregularities (for e.g., anterior tags, adherence of the capsule to the underlying lens material, prominent demarcation line) with higher pulse energy settings using LenSx Laser System, (Alcon Laboratories, Inc.) or Lensar Laser System, (Lensar, Inc. $)^{11,25}$. In contrast, cutting edges of capsulotomies performed using lower pulse energy $(5 \mu \mathrm{J})$ were found to be smoother and rounder ${ }^{11}$. The curved contact patient interfaces can create corneal folds that have been associated with incomplete capsulotomies during laser cataract surgery ${ }^{13}$.

Williams G.P. et al. showed that the low energy FEMTO LDV Z8 created circular, rupture resistant and smooth capsulotomies in both porcine and human globes ${ }^{4}$. Pisciotta A. et al. reported highly continuous morphology of capsule edges which was attributed to the low energy/high frequency properties of the laser pulse, combined with an overlapped pulse pattern ${ }^{26}$. Furthermore, Schwarzenbacher et al. have demonstrated that especially low pulse energy lasers do not significantly increase the level of inflammatory cytokines (interleukin), which indicates low damage to the surrounding tissue ${ }^{24}$. Another article by Verdina T. et al. reported, that low energy capsulotomy group had higher circularity and stability of capsulotomy diameter compared with the standard bimanual microincision cataract surgery technique over the 18-month observation period and was also associated with lower PCO rates ${ }^{27}$. Also, a report evaluating learning curve with the FLACS found three capsule related complications with the low energy femtosecond laser during initial 60 cases, and none after overcoming the learning curve ${ }^{22}$.

As in line with literature, in this study the lower pulse energy settings and the high frequency of Z8 FLACS system and thus the overlapping precisely placed laser spots compared with LenSx showed significantly better capsulotomy outcomes. The same effect was also seen in the lower number capsular tears and incomplete treatment pattern.

Completeness of $\mathrm{CCl}$. In the present study, we also investigated the effect of two laser systems on the completeness of main and side port incisions. The results indicated slightly higher percentage of eyes with complete CCIs in Z8 group (although the difference was not statistically significant), compared to LenSx group. It is important to note that the completeness and ease of opening of corneal incisions depend on their proximity to the limbus. While the limbal incisions are desirable with regard to the surgically induced astigmatism, they might be difficult to open as the cornea gets thicker and less transparent towards the periphery. The incisions created by FEMTO LDV Z8 are mostly placed closer to limbus as compared with the LenSx incisions, which are created rather corneal, due to different centration and docking mechanisms. Therefore, the comparable outcomes between two laser systems in terms of completeness of CCI and side-ports must be interpreted considering, that the distance to limbus was not taken into account when the incisions quality was evaluated.

Incidence of sub-conjunctival hemorrhage. Subconjunctival hemorrhage after femtosecond laser surgery has been associated with the docking process (scleral contact of the interface) and strong suction pressure applied at the patient interface ${ }^{9}$. In an experimental study, liquid optical interface (LOI) performed better in terms of elimination of corneal folds, improved globe stability, reduced subconjunctival hemorrhage and lower IOP elevation, compared to the curved contact lens (CCL) interface system ${ }^{13}$. Consistent with these findings, the incidence of subconjunctival hemorrhage was found to be significantly higher with contact corneal applanation based LenSx group, compared to Z8 group that employs non-applanation fluid filled patient interface $(63 \%$ vs $1 \% ; \mathrm{p}<0.001)$ in this study. Similarly, previous publications also reported significantly lower incidence of sub-conjunctival hemorrhage with liquid interface systems, compared to CCL interface system ${ }^{15,28}$. With the availability of advanced presbyopia correcting intraocular lens (IOLs) and changing practice patterns, there is a gradual shift in age of the patients undergoing cataract/refractive lens exchange surgeries. The younger and cosmetically more aware patients are likely to value the lower probability of post-FLACS subconjunctival hemorrhage with low energy Z8 laser, thereby increasing patient satisfaction in such patient population.

Intraoperative miosis. Intraoperative pupil miosis is the most frequently reported complication during FLACS. It is hypothesized that pupil miosis is linked to the release of prostaglandin and other inflammatory mediators by the ciliary body in response to dissipation of laser energy, leading to increase in temperature, shock waves and vibrations ${ }^{29}$. Laser pulse energy is thought to play an important role in the degree of inflammatory response generated by the femtosecond laser ${ }^{30-33}$. It has been reported that decrease in applied laser pulse energy reduces the damage to surrounding tissues ${ }^{11,34}$. Supporting this theory, previous studies have reported a substantially high incidence of intraoperative miosis (as high as 32\%) with the use of high energy femtosecond laser systems $^{7-9}$. Consistent with the literature, the incidence of intraoperative miosis was found to be significantly higher in LenSx treated eyes, compared to Z8 group (19\% vs $1 \% ; \mathrm{p}<0.001)$ in this study. Apparently, the low energy Z8 laser would induce minimal collateral damage to surrounding tissue, thus ensuing lower amounts of prostaglandin release, thereby reducing the risk of pupillary miosis during the surgery ${ }^{32}$, compared with high energy laser systems $s^{31,33,35,36}$. In agreement with these findings, a recent study reported no significant changes in pre- and post-laser treated pupil area with low energy Z8 FLACS system ${ }^{37}$. Conversely, Diakonis et al. revealed significant pupillary miosis with 3 different high energy femtosecond laser platforms ${ }^{38}$.

Although, we did not evaluate the levels of prostaglandins released following treatment with the two laser systems in this study, a meeting abstract presented at ARVO 2018 annual meeting reported only a slight increase in prostaglandins with a low energy femtosecond laser system (median value: $20.15 \mathrm{pg} / \mathrm{ml}$ after 5 min of laser 
pre-treatment $)^{24}$. Whereas, another publication reported markedly high levels of prostaglandins with the use of high energy laser systems (mean values: $330.6 \mathrm{pg} / \mathrm{ml}$ after full treatment including capsulotomy and fragmentation; $362.4 \mathrm{pg} / \mathrm{ml}$ after laser capsulotomy) ${ }^{38}$.

Another likely reason for significantly high miotic effect observed with the LenSx laser group could be due to the extended time lapse between femtosecond laser pretreatment and the further surgical steps involved with this laser system. Conventional non-mobile laser systems are usually placed in a different room and after the pre-treatment the patient needs to be transferred to the sterile operating room where phacoemulsification is performed, thus necessitating a transition time for patient transfer and sterile draping. In some settings, the patient may have to move up and the operating room may be a hallway away from the laser room. Whereas, with mobile Z8 laser system (housed in the same room), phacoemulsification can be performed immediately following laser application, thereby causing no delay between femtosecond laser pre-treatment and phacoemulsification ${ }^{39}$. In addition, the entire procedure is carried under sterile conditions of the operating room. As such, housing the femtosecond laser and the operating table in the same room is most suitable ${ }^{40}$, and must become the only accepted option.

Pre-treatment with topical NSAIDs has been suggested to lower prostaglandin release, thus may have potential benefit of preventing pupil miosis ${ }^{32,36,41}$. In this study, preoperative NSAID eyedrops regimen was uniform for the two laser groups, thus eliminating any potential bias due to differences in NSAID regimen responsible for significant difference in intraoperative miosis between the two laser groups. In both groups all eyes received NSAIDs drops combined with the mydriatics prior to surgery. Given the lower incidence of intraoperative miosis in the Z8 group, patients with documented NSAID allergy may benefit from the use of the low energy Z8 laser. The hypothesis is supported by the findings of Mirshahi et al., that did not detect statistically significant changes in the pupil area after laser pre-treatment with the low energy FEMTO LDV Z8 $8^{37}$.

Limitations. Although patient demographics such as age and sex were comparable between the two laser groups; we did not compare preoperative ocular characteristics such as axial length, nuclear sclerosis grade, copathologies and visual outcome which may have influenced the study outcomes and therefore could be a potential limitation of this study. Also, the two lasers were operated using the default settings recommended by the manufacturers in an attempt to achieve optimal outcomes with the respective lasers (Table 1). Besides the resection height of the capsulotomy being centered on the anterior capsule, completeness of the capsulotomy is more likely a function of overlapping adjacent laser spots ${ }^{23}$. The variation in the anterior capsule thickness of a few microns is unlikely to affect the completeness of the capsulotomy, although it cannot be ruled out completely ${ }^{42}$. Future studies with comparable capsulotomy diameters may help validate the findings of the present study. The two lasers place incisions at different distances to the limbus. Incisions created by LenSx are rather corneal, whereas the incisions created by FEMTO LDV Z8 are mostly placed closer to the limbus. The corneal incisions are expected to be easier to open, and incisions closer to the limbus are expected to be harder due to less transparent cornea in the periphery. Thus, the comparable outcomes between two laser systems in terms of completeness of CCI and side-ports must be interpreted considering that default laser settings were used and the distance to limbus was not taken into account when the incisions quality was evaluated. Another limitation of this study could be that the visualisation of the capsulotomy margin was chosen as criterion of absence of intraoperative miosis, instead of directly measuring the pupil area or diameter.

\section{Conclusion}

To summarize, low energy Z8 laser system performed significantly better in terms of completeness of capsulotomy, intraoperative miosis and sub-conjunctival hemorrhage, compared with high energy LenSx laser under default laser settings recommended by the manufacturers; however, CCI outcomes were found to be comparable. The authors associate these findings to the low energy laser being gentler on the ocular tissue and causing low inflammation. Future technological innovations and prospective studies in different aspects of low energy femtosecond lasers are expected to further improve the safety and effectiveness of the procedure and allow faster visual rehabilitation and greater patient satisfaction.

Received: 6 September 2020; Accepted: 20 April 2021

Published online: 04 May 2021

\section{References}

1. Mohammadpour, M., Erfanian, R. \& Karimi, N. Capsulorhexis: Pearls and pitfalls. Saudi J. Ophthalmol. 26(1), 33-40 (2012).

2. Titiyal, J. S., Kaur, M., Singh, A., Arora, T. \& Sharma, N. Comparative evaluation of femtosecond laser-assisted cataract surgery and conventional phacoemulsification in white cataract. Clin. Ophthalmol. 10, 1357-1364 (2016).

3. Pantanelli, S. M. et al. Anterior capsulotomy outcomes: A comparison between two femtosecond laser cataract surgery platforms. J. Refract. Surg. 31(12), 821-825 (2015).

4. Williams, G. P. et al. The effects of a low-energy, high frequency liquid optic interface femtosecond laser system on lens capsulotomy. Sci. Rep. 6, 24352 (2016).

5. Abell, R. G. et al. Femtosecond laser-assisted cataract surgery versus standard phacoemulsification cataract surgery: Outcomes and safety in more than 4000 cases at a single center. J. Cataract. Refract. Surg. 41(1), 47-52 (2015).

6. Abell, R. G. et al. Anterior capsulotomy integrity after femtosecond laser-assisted cataract surgery. Ophthalmology 121(1), 17-24 (2014).

7. Bali, S. J., Hodge, C., Lawless, M., Roberts, T. V. \& Sutton, G. Early experience with the femtosecond laser for cataract surgery. Ophthalmology 119(5), 891-899 (2012).

8. Chang, J. S. et al. Initial evaluation of a femtosecond laser system in cataract surgery. J. Cataract. Refract. Surg. 40(1), 29-36 (2014).

9. Nagy, Z. Z. et al. Complications of femtosecond laser-assisted cataract surgery. J. Cataract. Refract. Surg. 40(1), 20-28 (2014).

10. Pepose, J. \& Lubatschowski, H. Comparing femtosecond lasers. Cataract Refract. Surg. Today. 10, 45-51 (2008). 
11. Mayer, W. J. et al. Cell death and ultrastructural morphology of femtosecond laser-assisted anterior capsulotomy. Invest. Ophthalmol. Vis. Sci. 55(2), 893-898 (2014).

12. De Giacinto, C. et al. Intraocular pressure changes during femtosecond laser-assisted cataract surgery: A comparison between two different patient interfaces. J. Ophthalmol. 2019, 5986895 (2019).

13. Talamo, J. H. et al. Optical patient interface in femtosecond laser-assisted cataract surgery: Contact corneal applanation versus liquid immersion. J. Cataract Refract. Surg. 39(4), 501-510 (2013).

14. Mayer, W. J., Klaproth, O. K., Hengerer, F. H. \& Kohnen, T. Impact of crystalline lens opacification on effective phacoemulsification time in femtosecond laser-assisted cataract surgery. Am. J. Ophthalmol. 157(2), 426-432 e421 (2014).

15. Rivera, R. P., Hoopes, P. C. Jr., Linn, S. H. \& Hoopes, P. C. Comparative analysis of the performance of two different platforms for femtosecond laser-assisted cataract surgery. Clin. Ophthalmol. 10, 2069-2078 (2016).

16. Latz, C., Asshauer, T., Rathjen, C. \& Mirshahi, A. Femtosecond-laser assisted surgery of the eye: Overview and impact of the lowenergy concept. Micromachines (Basel). 12(2), 122 (2021).

17. Pajic, B., Cvejic, Z. \& Pajic-Eggspuehler, B. Cataract surgery performed by high frequency LDV Z8 femtosecond laser: Safety, efficacy, and its physical properties. Sensors (Basel). 17(6), 1429 (2017).

18. Yamazaki, K. et al. Efficacy of femtosecond laser-assisted cataract surgery for cataracts due to atopic dermatitis. Case Rep. Ophthalmol. 12(1), 41-47 (2021).

19. Gavris, M. M., Belicioiu, R., Olteanu, I. \& Horge, I. The advantages of femtosecond laser-assisted cataract surgery. Romanian J. Ophthalmol. 59(1), 38 (2015).

20. Roberts, T. V., Lawless, M., Bali, S. J., Hodge, C. \& Sutton, G. Surgical outcomes and safety of femtosecond laser cataract surgery: A prospective study of 1500 consecutive cases. Ophthalmology 120(2), 227-233 (2013).

21. Pajic, B., Vastardis, I., Gatzioufas, Z. \& Pajic-Eggspuehler, B. First experience with the new high-frequency femtosecond laser system (LDV Z8) for cataract surgery. Clin. Ophthalmol. 8, 2485-2489 (2014).

22. Cavallini, G. M. et al. Femtosecond laser-assisted cataract surgery with bimanual technique: Learning curve for an experienced cataract surgeon. Int. Ophthalmol. 39(1), 1-9 (2019).

23. Riau, A. K. et al. Comparative study of nJ- and muJ-energy level femtosecond lasers: Evaluation of flap adhesion strength, stromal bed quality, and tissue responses. Invest. Ophthalmol. Vis. Sci. 55(5), 3186-3194 (2014).

24. Schwarzenbacher, L., Schartmueller, D., Leydolt, C. \& Menapace, R. Intraindividual comparison of proinflammatory cytokines (IL-1 $\beta$, IL-6) and total-prostaglandin (PG) following Femtosecond Laser-assisted Cataract Surgery using a Low-energy, Highfrequency Femtosecond Laser-Device compared to Manual Cataract Surgery. Investig. Ophthalmol. Vis. Sci. 59(9), 4789-4789 (2018).

25. Mastropasqua, L. et al. Scanning electron microscopy evaluation of capsulorhexis in femtosecond laser-assisted cataract surgery. J. Cataract Refract. Surg. 39(10), 1581-1586 (2013).

26. Pisciotta, A. et al. Anterior capsule of the lens: Comparison of morphological properties and apoptosis induction following FLACS and standard phacoemulsification surgery. Biomed. Res. Int. 2018, 7242837 (2018).

27. Verdina, T. et al. Long-term evaluation of capsulotomy shape and posterior capsule opacification after low-energy bimanual femtosecond laser-assisted cataract surgery. J. Ophthalmol. 2020, 6431314 (2020).

28. Khodabakhsh, A. J. \& Hofbauer, J. Contralateral eye comparison of the phacoemulsification metrics, patient experience and clinical outcomes in patients undergoing bilateral cataract surgery with two commonly used femtosecond laser systems. Clin. Ophthalmol. 12, 1391-1398 (2018).

29. Popiela, M. Z. et al. Factors influencing pupil behaviour during femtosecond laser assisted cataract surgery. Cont. Lens Anterior Eye 42(3), 295-298 (2019).

30. Chen, H. et al. Topical $0.1 \%$ bromfenac sodium for intraoperative miosis prevention and prostaglandin E2 inhibition in femtosecond laser-assisted cataract surgery. J. Ocul. Pharmacol. Ther. 33(3), 193-201 (2017).

31. Jun, J. H., Yoo, Y. S., Lim, S. A. \& Joo, C. K. Effects of topical ketorolac tromethamine $0.45 \%$ on intraoperative miosis and prostaglandin E2 release during femtosecond laser-assisted cataract surgery. J. Cataract Refract. Surg. 43(4), 492-497 (2017).

32. Liu, Y. C., Setiawan, M., Ang, M., Yam, G. H. F. \& Mehta, J. S. Changes in aqueous oxidative stress, prostaglandins, and cytokines: Comparisons of low-energy femtosecond laser-assisted cataract surgery versus conventional phacoemulsification. J. Cataract Refract. Surg. 45(2), 196-203 (2019).

33. Schultz, T., Joachim, S. C., Kuehn, M. \& Dick, H. B. Changes in prostaglandin levels in patients undergoing femtosecond laserassisted cataract surgery. J. Refract. Surg. 29(11), 742-747 (2013).

34. Ostovic, M., Klaproth, O. K., Hengerer, F. H., Mayer, W. J. \& Kohnen, T. Light microscopy and scanning electron microscopy analysis of rigid curved interface femtosecond laser-assisted and manual anterior capsulotomy. J. Cataract Refract. Surg. 39(10), 1587-1592 (2013).

35. Kiss, H. J. et al. One-day use of preoperative topical nonsteroidal anti-inflammatory drug prevents intraoperative prostaglandin level elevation during femtosecond laser-assisted cataract surgery. Curr. Eye Res. 41(8), 1064-1067 (2016).

36. Schultz, T., Joachim, S. C., Szuler, M., Stellbogen, M. \& Dick, H. B. NSAID pretreatment inhibits prostaglandin release in femtosecond laser-assisted cataract surgery. J. Refract. Surg. 31(12), 791-794 (2015).

37. Mirshahi, A. \& Ponto, K. A. Changes in Pupil Area During Low-energy Femtosecond Laser Assisted Cataract Surgery. J. Ophthalmic Vis. Res. 2019, 251-256 (2019).

38. Schultz, T., Joachim, S. C., Stellbogen, M. \& Dick, H. B. Prostaglandin release during femtosecond laser-assisted cataract surgery: Main inducer. J. Refract. Surg. 31(2), 78-81 (2015).

39. Vasquez-Perez, A., Simpson, A. \& Nanavaty, M. A. Femtosecond laser-assisted cataract surgery in a public teaching hospital setting. BMC Ophthalmol. 18(1), 26 (2018).

40. Dick, H. B. \& Gerste, R. D. Plea for femtosecond laser pre-treatment and cataract surgery in the same room. J. Cataract Refract. Surg. 40(3), 499-500 (2014).

41. Ventura, B. V., Rabello, L. P., Silvestre, F. \& Ventura, M. C. Efficacy of preoperative nonsteroidal anti-inflammatory drug and the re-dilation technique in minimizing miosis after femtosecond laser in cataract surgery. Arq. Bras. Oftalmol. 82(2), 111-118 (2019).

42. Barraquer, R. I., Michael, R., Abreu, R., Lamarca, J. \& Tresserra, F. Human lens capsule thickness as a function of age and location along the sagittal lens perimeter. Invest. Ophthalmol. Vis. Sci. 47(5), 2053-2060 (2006).

\section{Acknowledgements}

None.

\section{Author contributions}

Conceptualization: H.L., Y.C.; Formal Analysis: H.L., Y.C., P.L.; Investigation: H.L., Y.C., P.L.; Methodology: H.L., Y.C.; Project administration: H.L., Y.C., P.L.; Validation: H.L., Y.C., P.L.; Writing一original draft: H.L., Y.C., P.L.; Writing-reviewing \& editing: H.L., Y.C., P.L. 


\section{Competing interests}

The authors declare no competing interests.

\section{Additional information}

Correspondence and requests for materials should be addressed to Y.-J.C.

Reprints and permissions information is available at www.nature.com/reprints.

Publisher's note Springer Nature remains neutral with regard to jurisdictional claims in published maps and institutional affiliations.

(c) (1) Open Access This article is licensed under a Creative Commons Attribution 4.0 International License, which permits use, sharing, adaptation, distribution and reproduction in any medium or format, as long as you give appropriate credit to the original author(s) and the source, provide a link to the Creative Commons licence, and indicate if changes were made. The images or other third party material in this article are included in the article's Creative Commons licence, unless indicated otherwise in a credit line to the material. If material is not included in the article's Creative Commons licence and your intended use is not permitted by statutory regulation or exceeds the permitted use, you will need to obtain permission directly from the copyright holder. To view a copy of this licence, visit http://creativecommons.org/licenses/by/4.0/.

(C) The Author(s) 2021 